\title{
Arbor
}

\section{¿Dios problemático?}

\section{Miguel García Baró}

Arbor CLXXI, 676 (Abril), 665-676 pp.

El final de la modernidad, ya con dos siglos de historia, es, desde el punto de vista de la religión y su filosofía, sobre todo la gran cuestión abierta de cómo pueda continuar la empresa de la emancipación del hombre después del fracaso del idealismo absoluto y de sus secuelas. Se trata de un tiempo que ha sido comparado con justicia al de una "segunda inocencia», donde importa esencialmente afrontar en toda su amplitud y seriedad el problema del mal y la posibilidad de una esperanza realmente dirigida a la salvación de Dios, y no a cualquier objetivo intramundano.

1. Tratar de la cuestión de Dios es siempre el camino más derecho para ir al fondo del problema de la realidad sin detenerse en lo secundario y sin dar rodeos inútiles, porque no es ni puede ser el ejercicio de un pensar como cualquier otro, sino el dificilísimo intento explícito de igualarse en la teoría a la tensión existencial suprema.

Siempre me ha atraído el encanto de aquella declaración de Simone Weil en la que recordaba su adolescencia: aquel tiempo en que, abrumada por el peligro extraordinario de resolver mal la cuestión de Dios, se decía a sí misma que lo único sensato era evitar su planteamiento. Constantemente he asociado esta advertencia con aquel dicho de luz y amor de Juan de la Cruz en que el santo se burla de (y se apena por) aquellos tantos que querrían que Dios no les costase «mas que hablar, y aun eso mal».

$\mathrm{Y}$ es que, ¿qué significa eso de igualar con el pensamiento la tensión existencial suprema?

Si se filosofa sobre Dios, no es en absoluto obligatoria partir de que lo que ha de hacerse es analizar los dos clásicos problemas (la existencia y 
la esencia de Dios) en un modo que haga abstracción de las religiones concretas, bien para situarse del todo al margen de ellas, o bien para elevarse por encima de todas ellas. No hay que prejuzgar que existan espacios al margen o por encima de la existencia religiosa, precisamente reservados para este extraño explorador de lo divino que puede ser el filósofo. Lo que en cambio sí dice, desde luego, la palabra «filosofía» es que en ella se trata de remontar a una lucidez sobre las raíces de toda otra lucidez que no es el estado corriente de nuestra vida. Quienes creemos por experiencia (claro que experiencia deficiente) en la realidad indudable de la filosofía, admitimos que pertenece a nuestra esencia el torpor de la estupidez, la imposibilidad de mantener realmente tensada la vida y despierta para todas sus posibilidades de energía. Reconocemos que aspiramos a vivir una existencia en la que se haya conseguido volver habitual un estado que, por desgracia, no nos es inmediatamente natural, y para el cual resulta muy difícil evitar las metáforas que aluden a la luz y la vigilia. Como si el estado en el que nos encontramos más habitualmente fuera el de ignorar nuestra situación auténtica.

Los aspirantes a la filosofía no podemos desconectar el factor lucidez de la representación que nos hacemos del estado de suprema tensión existencial, sólo desde el cual puede ser Dios o el Misterio nuestro referente intencional (en lo que, por cierto, estamos de acuerdo con cualquier hombre religioso). Y, por cierto, esa tensión suprema puede muy bien consistir en hallar activísimamente el acceso a una serenidad, a una pasividad absolutamente hiperbólica.

No hay, pues, que partir de la idea de que filosofar sobre Dios debe consistir, en primer lugar, en olvidarse de las religiones, dando por entendido que no hay religión histórica concreta que no sea una aproximación errónea a su peculiar objeto.

2. ¿Es que sólo se ha debido a los movimientos peculiares de las ideas el hecho de que esté finalizando la edad que ha confiado en la inocencia y la suficiencia de la razón para emancipar al hombre del mal? Las convulsiones y las desesperanzas del final de la modernidad están ligadas a que han sucedido muchos de aquellos acontecimientos que eran la consecuencia de los principios modernos y a que se tiene la certeza de que estas consecuencias son de hecho fatales para sus lejanos principios, de tan justa e inocente apariencia. No es precisamente que la historia del siglo que ha terminado se limite a una aséptica reductio ad absurdum de sus premisas culturales: más bien se trata de una horrenda reductio ad malum. Claro está que el mal (el sufrimiento, la culpa) es el auténtico absurdo; y es enormemente probable que todas las grandes crisis entre épocas históricas hayan ocurrido según este mismo esquema de la reductio ad malum. 
3. ¿No hemos ganado así alguna verosimilitud acerca de que la vieja filosofía pueda ser, como sostenía entre guerras Rosenzweig, más bien un tósigo que nos impide vivir valientemente en el gran día de Dios, suficientemente sensibles tanto para el mal como, por ello mismo, para los misterios de bondad de la relación interpersonal?

A través de la desgracia y la vergüenza, ¿no podemos empezar a pensar que nuestra historia arriba ahora a una suerte de segunda inocencia, en la que no sólo cabe lo que por tal entendía estrictamente Nietzsche (o sea, el ultrahombre que ha atravesado la consumación del nihilismo, una vez muerto Dios y sepultado su terrible cadáver), sino también, como escribió hace pocos años Schillebeeckx, la era post-crítica de las religiones, en la que podemos de nuevo caminar con Dios por el Jardín como con el Cercano en quien confiamos y que es nuestro Familiar?

¿Qué aspecto tiene para la filosofía este paisaje que quizá vislumbramos ya?

Naturalmente, toda prevención será poca contra el más evidente riesgo que toma sobre sí aquel que se ve llevado de alguna manera al juicio de la historia inmediata: el peligro de que sus limitaciones lo conduzcan de regreso a algo que él ignora que ya ha sido probado hasta el fondo y hallado falto. En toda crisis de final de época revive el recurso de que ya antes existió lo que nos tiene que servir de modelo para salir adelante. En ningún momento como en el momento de la crisis cobra tanta vida, incluso, el espejismo de que se ha dejado tras sí, dentro mismo de la historia, el arquetipo de todas las épocas, irrecuperable por ninguna.

Por otra parte, la audacia de un pensamiento que se lanza hacia lo futuro con máxima conciencia de todo el pasado se trunca si no realiza su esfuerzo a la vez en todas las vertientes del conocimiento, mutatis mutandis. En la actualidad, esto significa, sobre todo, que los cultivadores de las ciencias positivas deben conseguir entender sus actividades no sólo a la luz de las discusiones lógicas y sociológicas de la filosofía contemporánea de la ciencia (lo cual ya sería un progreso notabilísimo respecto de lo que de hecho sucede), sino que no pueden mantenerse despectiva o ignorantemente al margen del apasionante camino recorrido por los saberes filosóficos, humanos y teológicos desde la crítica kantiana hasta el presente. Además de que sea ridícula la muy extendida admiración por las ciencias duras como si fueran oráculos divinos, en la comprensión crítica de sí mismo por parte del científico particular se juega un capítulo decisivo del equilibrio y el progreso de toda la cultura de nuestra época.

4. La edad moderna se cifra en el proyecto de la total autoliberación del hombre por el hombre mismo. 
¿Quién podrá negar que la historia debía, necesitaba conocer una fase como la edad moderna (o sea: el proyecto de total liberación del hombre por el hombre mismo) y que debía además experimentar hasta el final las posibilidades de semejante proyecto?

El racionalismo hacía coincidir la autoliberación humana con el universal imperio de la razón calculante intemporal e inespacial, bajo la cual habían de someterse no sólo las múltiples confesiones cristianas de la Europa dividida por las guerras de religión, sino también toda la variedad de las culturas en cuyo contacto se estaba ampliando el horizonte histórico de la cristiandad. Este sometimiento ha supuesto con frecuencia el aplastamiento de la variedad, y ha repercutido en el cristianismo, no sólo purificándolo, sino también volatilizándolo.

$\mathrm{El}$ hombre es en este programa simultáneamente el sujeto y el objeto de la acción emancipadora. El supuesto básico es que el ideal que hay que realizar, e incluso el poder eficaz para llevarlo a cabo, estén desde un comienzo en quien emprende viaje. Tal ideal y tal poder se dejan comprender en un solo término: se trata de la plena identidad del hombre consigo mismo, o sea, del logro perfecto de su destino, de la liberación de toda enajenación de su ser, de toda (auto)alienación. El hombre en quien comienza el proceso de emancipación se compone a la vez de humanidad que debe ser superada (los idola baconianos) y humanidad arquetípica o auténtica, o sea, definición ideal, vocación inalienable, que es a un mismo tiempo causa final, eficiente y ejemplar de la autohumanización o autoliberación.

Si es verdad que Kant hizo entrar al hombre moderno en la plenitud de su finitud, sólo fue posible porque, dicho en la lengua de Espinosa, creyó poder probar que ni el Pensamiento ni la Extensión son atributos infinitos de la Sustancia Infinitamente Infinita. Pero también y al mismo tiempo porque su crítica consiguió reunir la Vida y la Razón, a las que Hume había declarado en conflicto irresoluble. Y ya que la Razón no es Atributo de la Sustancia, tampoco le es posible al idealismo crítico declarar absoluta la poderosidad de la Vida irracional, del Deseo, del impulso, el instinto y la pasión.

El idealismo kantiano es a un tiempo crítica de la teología racionalista en cualquiera de sus formas (teísta, deísta, ateísta y panteísta) y crítica del vitalismo empirista. Ahora bien, el sujeto que realiza esta crítica es ante todo la razón finita, de modo que a ésta compete el papel de principio de la integración de la finitud toda del hombre. Y no es sólo razón teo-rética sino, más radicalmente, razón práctica.

El destino del hombre no es trascendente, sino finito; pero ello no afloja la tensión en que ha de consistir la historia de la autoliberación hu- 
mana, sino que pretende conducirla a su máximo. Si el ideal se traslada a lo Más Allá, el núcleo del esfuerzo se convierte en un antiesfuerzo: es el quietismo, el místico fatalismo, que realmente consiste en abandonarse a lo no-humano, o sea, en dejar del todo a un lado el proyecto de autoemancipación. Si todas las posibilidades del ser del hombre son finitas, abandonarse en lo no humano tiene que ser cosa absolutamente diferente de ponerse en las manos de Dios: sólo será en realidad descender de la condición humana y hacerse uno mismo el esclavo de cuanto de animal y de muerto se oculta en las zonas de tiniebla del hombre empírico y necesitado de liberación.

Además, el idealismo crítico lleva a máxima tensión real la historia de la autoliberación, porque en él el ideal de la autohumanización queda siendo para siempre un ideal. El hombre empírico, o sea, el hombre concreto, es, además de razón finita, también naturaleza, sensibilidad, pasividad del placer y el dolor; y, sobre todo, ha dado entrada, como resorte de su acción, a una máxima o principio práctico que ya siempre concede la palabra a las inclinaciones egoístas y no deja que hable pura y sola la razón. La adopción de esta máxima, por cuya virtud es siempre trabajoso para el hombre dejar que sea el santo respeto a la ley moral el solo fundamento de determinación de su voluntad, es el pecado de origen del hombre.

De hecho, la tensión moral de la historia es tanta gracias a que ningún hombre llega a conocerse éticamente a sí mismo tal y como es. Este velo de ignorancia que nada puede conseguir que levantemos, nos deja en la sospecha de si no actuaremos siempre movidos por el egoísmo, pero también nos impide desesperar, al mismo tiempo que nos impide jactarnos de que la filosofía de la historia tenga estatuto de ciencia. Y este obstáculo es en realidad un elemento de salud fundamental, que previene contra la fanática certeza de estar realizando, sin duda, el bien, pese a los dolores y la sangre de la revolución que comporta tanta bondad.

La autoliberación es, pues, en la perspectiva del idealismo crítico, una infinita tarea desinteresada, un deber infinito para el hombre, quien, sin embargo, conoce que respetando la santidad de este deber no rinde culto a ninguna fuerza inferior, maligna y regresiva, sino a la humanidad pura misma, o sea: a la libertad finita (autónoma, sí, pero ciudadana del reino de los fines o mundo inteligible, y no cabeza de este reino).

Ahora bien, esta visión del ser del hombre ciudadano a la vez del reino de la naturaleza y del reino de la libertad, es evidente que exige que el tiempo no se conciba primordialmente en los términos en que lo define la mecánica universal de la ciencia física de la naturaleza. Por mucho que la tarea de la incesante lucha de la razón contra la «inclinación» no 
sea un espectáculo al que podamos asistir directamente en la conciencia, ya que la conciencia empírica es parte de la naturaleza, esa tarea, esa tensión nos impone la necesidad de pensar la historia y su temporalidad en términos de historia trascendental de la libertad. Si, como la Estética transcendental propone, el tiempo sólo perteneciera a la finitud «empírica», también sería sólo una cuestión «empírica» la tensión hacia el ideal.

Se necesita, pues, pensar con más profundidad la unidad de la subjetividad finita. No cabe escindirla en «empírica» $\mathrm{y}$ «trascendental», si es verdad que la razón pura es, al tiempo, práctica. De aquí que el idealismo crítico absoluto de Fichte sea en su esencia «crítica de toda revelación» y, por fin, fundamento de toda revolución.

Sólo que mantiene el término de idealismo «crítico» para aludir precisamente a la diferencia entre Dios y la finitud, y así condena al nihilismo todo el saber, dado que, en el fondo, el «saber absoluto» únicamente se puede entender a sí mismo como automanifestación y autorrealización de la finitud, como destino o ser del hombre. La tarea no estará terminada mientras quede alguna fisura entre la historia trascendental y la historia empírica. La subjetividad finita en vías de autoliberación no puede conformarse hasta que llega a pensar como integrantes de su empresa (de la Historia de la Libertad) todos los «fenómenos». La historia empírica, la naturaleza, cada instante y cada cosa y cada idea, cada alegría y cada dolor, cada proyecto y cada vida y cada muerte integran la Historia, la Autoconsumación del Espíritu, la Autoliberación. No cabe tomarse en serio con radicalidad absoluta esta historia en tanto se pretenda que el idealismo absoluto sea crítico en el sentido de finito. La última distinción que debe ser abolida es la que el Saber Absoluto trazaba entre la Historia y Dios. Semejante «reserva escatológica» impregna de arbitrariedad a la misión de la Ilustración moderna y de escepticismo a la filosofía que la fundamenta. La Historia es Dios en devenir. No otro es el significado real de la Encarnación de Dios. La filosofía cristiana (hegeliana) deja definitivamente atrás la Antigüedad y la Edad Media cuando por fin piensa la Encarnación de Dios en unidad con la humanización del hombre.

¿Cómo pudo, entonces, ocurrir que esta culminación de la modernidad comportara a la larga como secuelas la guerra y la catástrofe $\mathrm{y}$, en definitiva, la diseminación del sentido?

5. El pensamiento contemporáneo y, en general, la Edad Contemporánea, el largo final de la modernidad, pueden entenderse, sin grave injusticia, como el conjunto de los esfuerzos por ser y pensar más allá de Hegel o contra Hegel (o sea, suficientemente al margen de Hegel).

La clave de estos esfuerzos es, a mi entender, la tesis central de la obra multiforme de Kierkegaard: que la salvación no puede ser la obra 
del hombre. Que la autoliberación tiene una condición decisiva: la de que su motor sea previamente liberado él mismo, e incluso mucho más: liberado de sí mismo. Kierkegaard situaba, para ello, en el primer plano la pecaminosidad de la libertad concreta humana o del ser hombre en tanto que tal, y la destacaba con el pensamiento de la trascendencia de la «existencia religiosa» respecto del mismo ideal de la razón pura práctica (el «estadio ético»).

La actualidad del problema al que remite el término «Dios» es, pues, vista a esta luz, la que posee la cuestión capital de la historia en el presente: el replanteamiento de las condiciones bajo las que está el proyecto de la «autoliberación del hombre». Me atrevo a sostener la tesis de que «Dios» significa primordialmente hoy aquello que libera de sí misma a la libertad creativa del hombre hasta constituirla, por ello, en auténtica libertad (finita). De aquí que, en uno de sus aspectos, la actualidad filosófica de Dios coincida con la que tiene la mutación verdaderamente contemporánea del concepto y la tarea de la filosofía -y, con él, de los conceptos y las tareas de la «teología», las «ciencias», el arte y, en consecuencia, absolutamente todos los componentes de la realidad en su más amplio sentido posible-. Desde luego, el concepto de la religión está también implicado en esta transformación propiamente histórica, y ello condiciona la perspectiva en que se entiende adecuadamente la nueva época como momento dominado por el fenómeno cultural del diálogo universal de las religiones -y los ateísmos y los agnosticismos-.

La importancia absoluta del judeo-cristianismo radica en el hecho de que es él quien ha enseñado al hombre explícitamente a adorar y a pensar a Dios como aquello que libera de sí misma a la libertad del hombre.

6. No parece que sean posibles más que dos alternativas: o autoliberación o autoenajenación. Y realmente, si no hubiera más, se trataría de un dilema tétrico, cuyas dos ramas conducen a la misma desesperación. Si se manifiesta irracional la exacerbación del proyecto moderno, hay que ver claramente que tampoco podrá hacerse racional por ninguna vía la recaída en la enajenación pura. Si es la verdad la que encuentra los límites críticos, la dialéctica de la Ilustración, sólo un suplemento de verdad podrá conducir más allá de lo criticado. Sólo la verdad de la edad moderna puede superar definitivamente a la edad moderna misma. En general, la auténtica historia es, sobre todo, la verdad del tiempo que ella «deja atrás».

Pues bien, la fórmula que habla de la liberación de la libertad humana respecto de sí misma, muy lejos de significar la condena de la libertad y la razón finitas, es el anuncio de su triunfo.

¿Cómo nos haremos con alguna concepción no inapropiada acerca de las realidades fundamentales que hay que pensar de nuevo: el tiempo, la 
historia, la libertad, la finitud, la razón, la verdad, la identidad humana, la alteridad divina, lo absoluto divino? Si no lo conseguimos, ¿cómo defender la significatividad de expresiones tales como «ser sí mismo sin pensarse centro absoluto de la realidad»; «ser cada vez más sí mismo por el procedimiento de que otro libere de sí»; una «segunda inocencia»...?

Es preciso aferrarse, sobre todo, a este pensamiento: la libertad finita únicamente puede ser liberada de sus fantasmas y sus perversiones, sólo puede ser devuelta libremente a sí misma como tal libertad finita, por una alteridad que, lejos de oponérsele enajenándola, la enseñe, por así decir, desde su centro mismo la verdad de su identidad. La libertad finita tiene que ser libertada para sí y colocada sobre su verdad propia únicamente por la virtud de una alteridad que sea el fundamento de su verdad y su ser, el centro libérrimo de su finitud libre.

7. Reflexionemos de nuevo sobre la naturaleza de las crisis de la historia.

Hemos dicho ya que en ellas lo que esencialmente sucede es que el mal, esto es, la experiencia concreta de la historia como mal, refuta la presunta verdad, al menos (o sobre todo) como verdad religiosa, o sea, como verdad referida a lo absoluto.

En primer lugar, esta afirmación significa que la verdad religiosa va ligada con el concepto del bien. No que toda verdad haya de ser consoladora y, en este sentido, benéfica; sino que si la verdad de la religión es tal, entonces es que el bien existe. Más aún: si es verdadera la religión, entonces es que el bien absoluto existe.

$\mathrm{Al}$ bien absoluto llama el hombre, habitualmente, salvación. Ésta no es sino el bien absoluto que afecta al hombre concreto en la historia, en la naturaleza, en la sociedad a las que pertenece o en medio de las cuales existe.

$\mathrm{Al}$ parecer, la salvación como verdad de la religión no consiente una definición perenne que sea algo más que una mera definición formal. Pero este fenómeno se debe positivamente a que la salvación no se agota en lo que un hombre concreto se representa como tal, por más que, indudablemente, tenga que tener que ver con esta su representación precaria, limitada, ambigua. La salvación-que-viene-de-Dios (así escribe Edward Schillebeeckx) imprescindiblemente debe hallarse en algo así como la prolongación de la imagen o del concepto de ella que posea el hombre al que se dirige. Sólo en tal caso puede ser recibida, escuchada, vivida como tal salvación-de-Dios. Pero en la prolongación, y nunca ya contenida en esa imagen o en ese concepto (que, en caso contrario, se vuelven verdaderos ídolos, como Rosenzweig o Marion o Levinas han dicho repetidamente). 
De este modo, la salvación-de-Dios está vinculada con la interpretación concreta que de sí mismo, en el interior de la naturaleza, la historia y la sociedad, tiene el hombre (un hombre, pero en tanto que miembro de estos conjuntos socio-culturales y naturales; y, por descontado, casi siempre, quizá, incluso, siempre se trate de una autocomprensión no explícita ni articulada lingüísticamente).

Pero la verdad de la religión sólo puede ser tal si, precisamente, la salvación en que consiste desborda esencialmente de las fronteras a sabiendas estrechas de la esperanza humana de salvación. El Dios de las religiones, el Misterio religioso no existe sino en la medida en que lo absoluto de su bondad como salvación del hombre (y del conjunto universal de la naturaleza, la sociedad y la historia) trasciende todos los proyectos posibles del hombre en orden a la mejora radical de todas las cosas. La perpetua paz de Dios tiene por principio que redoblar hasta lo infinito, hasta lo indecible, la paz perpetua que quizá un día el hombre -obedeciendo en esto, justamente, la voluntad eterna de Dios- consiga establecer en y con el Universo.

Pero -tercer momento- la hermenéutica de la verdad religiosa necesita, entonces, de un fundamento ulterior. Si la salvación-de-Dios sólo es anticipable imperfectamente en las experiencias concretas de máxima dicha y, sobre todo, en las esperanzas que, encendidas por esas experiencias, iluminan de alguna manera al creyente la ruta insondable de la trascendencia, ello depende, sin duda, de la masiva experiencia del mal en que consiste, en definitiva, la estancia (constante y esencial) del hombre en la finitud, en el mundo, en lo no-divino.

No quiero decir con esto que la experiencia del mal esté siempre y por naturaleza consumada en todo hombre. Lo cierto es lo contrario. Pero lo que sucede es que en la «anticipación» del mal excesivo que es la concreta vivencia de los males de la vida está ya enteramente presente la esencia de la experiencia del mal («el dolor»), mientras que en las experiencias prolépticas del bien lo único que nos cabe poseer de la esencia de la experiencia del bien («la salvación») es sólo, justamente, una anticipación lejana de ella.

La «experiencia contrastante del mal» es la base de la hermenéutica que se abre a la verdad de las religiones. La esencia dada ya del dolor posee varios otros componentes, pero uno de ellos es el «veto absoluto» (la expresión es de Schillebeeckx) que suscita en quien es su sujeto. Del mal presente hay que huir. Mejor dicho: el absurdo de negatividad que vivo en el dolor no sólo no debería existir, no tiene derecho a existir, sino que me compromete a combatirlo sin cuartel. Si el hombre estuviera abandonado a sus propias fuerzas, este compromiso sería el exclusivo sentido 
supremo de la existencia; pero, desde luego, un desesperado sentido, en la medida en que el dolor no es un asaltante exterior del hombre, sino un elemento omnipresente, un componente «esencial» de la experiencia humana: aquel que precisamente constituye su finitud. ( $\mathrm{O}$ es que la finitud es sólo la limitación espacio-temporal y causal de la existencia? No, sino que es la condición insuperable de estar sumido el hombre en la experiencia de que la salvación está ausente: de que Dios aún no «reina», como dice la metáfora apocalíptica dominante del anuncio evangélico de Jesús de Nazaret).

Pero lo que es capital para la «filosofía de la religión» en estos hechos es que conozco el mal y el dolor y de su experiencia constante -poco más o menos en carne viva y más o menos combinada con la anticipación del bien- brota una respuesta también constante (aunque susceptible de olvido y preterición): el absoluto veto al mal, que no significa sólo la huida de él, sino que, por contener la certeza de que no debiera existir, también comporta la exigencia de aniquilarlo. Para lo cual no tiene el hombre que considerarse limitado a sus propias fuerzas, que son demasiado exiguas para la empresa (ya que él es de suyo ser afectado por el mal, y no inocencia, justicia, chispa divina en un mundo de mal ajeno e él).

El reconocimiento auténtico de la finitud, dolorosidad o no-divinidad del ser del hombre en el conjunto de la sociedad, la naturaleza y la historia hace de la «experiencia contrastante del mal» y el "veto absoluto» que implica el origen mismo del clamor por la salvación-que-viene-deDios (y prolonga, sin embargo, el furioso esfuerzo heroico del hombre por «salvar» él mismo este mundo). El mal debe ser aniquilado. Exige en su contra todas mis fuerzas. Pero estas fuerzas mías participan del poder de su enemigo. He aquí entonces que en el centro de mi ser se eleva un clamor que atraviesa mi vida, la historia, toda la naturaleza, las culturas todas, para ir a unirse en lo oscuro con aquel Bien Absoluto que me lo hace lanzar. Habla por esto Levinas de una más que arcaica an-árquica alianza entre el Bien y el hombre.

Este clamor mío es mi centro y, a la vez, no soy simplemente yo ni es sólo cosa de «este mundo». Pero, en la medida en que también eso soy yo, es una exigencia precaria, ambigua, que se deja empañar y extraviar en cuanto, por decirlo imaginativamente, se aleja de su centro para internarse en la maleza de mi libertad, mi finitud, mi conocimiento, mi voluntad y mis esperanzas y valoraciones.

Anterior al mal y al dolor es este centro vulnerable o sensible -y, a la vez, invulnerable-. Sólo porque el hombre experimenta el mal en su maldad, sólo porque la existencia del hombre es (también) «dolor» esencial, sabemos de este espíritu que exige un futuro de Dios para todas las co- 
sas que sufren. El mal es el contraste, el azogue en el espejo. En la superficie radiante de éste no está sólo mi rostro, sino la luz por la que el azogue y mi rostro cumplen en el espejo sus funciones.

En todo caso, por la realidad certísima del mal -que amenaza de continuo con crecer y cambiar su cualidad hasta el sufrimiento insoportabledescubrimos que no somos redentores de nosotros mismos ni de nadie ni nada, pero que nuestro ser es un no al mal que salta infinitamente más allá de las fronteras del mundo. Y que, por esto mismo, menos que nada consiente la cosificación o mundanización de Dios, en el sentido de su plena y definitiva identificación con cualquier entidad, estructura, proceso o historia intramundanos. Dios no es jamás ni esto ni aquello, porque el mal continúa también allí -es decir, porque la salvación absoluta no reina todavía-. Toda experiencia de bien necesita siempre ser enmendada y traspasada. Necesita ser descubierta como, simultáneamente, dolor en algún modo, para quedar así abierta siempre, cada vez más, a la Presencia Divina Absoluta en cuanto Futuro Absoluto. Toda imagen de Dios tiene que ser superada; toda reificación de la salvación tiene que ser reformada, o, mejor, debe constantemente ser purificada. Porque no es que esté infinitamente separada de Dios, sino, más bien, está soportada en su ser-creador justamente en la medida en que está abierta al Futuro Absoluto de Dios, justamente en la medida en que es un signo profético de la venida del Reino de Dios, y no únicamente mal sin sentido.

Pero el mayor de los signos es aquel que a todos los demás los interpreta como tales: el hombre concreto, por cuanto él es experiencia del mal contrastante y, por lo mismo, posee en su centro la reclamación de la existencia patente de Dios. El ya ahora del siempre todavía no de la salvación-de-Dios es el hombre mismo en su centro invulnerable. $Y$ en este sentido la imagen única adecuada de Dios en el hombre es este centro absoluto, interior intimo meo, superior supremo meo. Adecuada, pero no trasladable a copia más clara; adecuada, pero sólo imagen. No el hombre mismo, sino sólo la luz del bien y el futuro: esto en su ápice y su núcleo que hace del hombre «duración real», o sea: apertura al Futuro Absoluto de la salvación.

Toda la vida del conocimiento y de la acción, de la creación y el sueño es para el hombre su personal relato de lo absoluto, su experiencia de los altos y los bajos de la esperanza y la decepción, la emoción y la resignación.

Pero todo esto no hace tampoco de los males magnitudes constantes u objetos inequívocos en la experiencia. No menos que el bien, el mal contrastante está sometido a la interpretación humana. Paralela a la hermenéutica del bien religioso es la hermenéutica del mal. Los rasgos es- 
tructurales del «dolor» y de la experiencia proléptica de la salvación se conservan en la mutación más llena de sentido (o sea, de misterio) que la historia muestra: la que experimentan los contenidos concretos de las experiencias contrastantes humanas, que es seguramente el hilo de oro de la historia de las religiones y, por lo mismo, el componente más propiamente histórico de la historia (de la finitud). 